\title{
CLINICAL EVALUATION AND MANAGEMENT OF PERITONITIS SECONDARY TO HOLLOW VISCUS PERFORATION
}

\author{
Dinesh H. N1, Sachin V2, Sreekanth ${ }^{3}$, Apurva Agarwal ${ }^{4}$ \\ ${ }^{1}$ Associate Professor, Department of General Surgery, Mysore Medical College and Research Institute. \\ ${ }^{2}$ Post Graduate, Department of General Surgery, Mysore Medical College and Research Institute. \\ 3 Post Graduate, Department of General Surgery, Mysore Medical College and Research Institute. \\ ${ }^{4}$ Post Graduate, Department of General Surgery, Mysore Medical College and Research Institute.
}

\begin{abstract}
BACKGROUND

Peritonitis is often caused by introduction of an infection into the otherwise sterile peritoneal environment through perforation of bowel, introduction of a chemically irritating material, such as gastric acid from a perforated ulcer. The different modes of presentation of cases may be misleading the diagnosis of its origin. Smoking and use of non-steroidal anti-inflammatory drugs are important risk factor for perforation. The objectives are to study the frequency of peritonitis secondary to hollow viscus perforation in relation to age, sex, anatomical location, symptoms and signs and its surgical management and complications of operative management.

The study has been based on the analysis of 50 cases of hollow viscus perforation cases fulfilling the criteria were randomly selected. Exclusion criteria were peritonitis due to oesophagus perforation and reproductive tract perforation. The diagnosis was made with history, clinical features and erect $\mathrm{x}$ ray abdomen.
\end{abstract}

\section{RESULTS}

Duodenum was the most common site of perforation and the highest number of patients were seen in the age group of 50 years and above irrespective of pathological conditions. Most of the patients presented 48 hours after onset of clinical symptoms. Laparotomy with closure of perforation with omental patch is the commonest method of surgical management. Lower respiratory tract infection is the most common complication observed.

\section{CONCLUSIONS}

The majority of perforation peritonitis cases in the study comprises of duodenal ulcer perforation. The ba sic principles of early diagnosis, prompt resuscitation and urgent surgical interventions still forms the cornerstone in the management of these cases. Educating the health professionals at primary health center regarding early diagnosis and early referral to tertiary center should be emphasized.

\section{KEYWORDS}

Gastrointestinal Perforation, Peritonitis, Exploratory Laparotomy.

HOW TO CITE THIS ARTICLE: Dinesh HN, Sachin V, Sreekanth, et al. Clinical evaluation and management of peritonitis secondary to hollow viscus perforation. J. Evolution Med. Dent. Sci. 2016;5(19):950-953, DOI: 10.14260/jemds/2016/221

\section{INTRODUCTION}

Peritonitis due to hollow viscus perforation is commonly encountered in surgical practice. It is defined as inflammation of serosal membrane that lines the abdominal cavity and the organs contained therein. Secondary peritonitis is often caused by introduction of an infection into the otherwise sterile peritoneal environment through perforation of bowel, introduction of chemically irritating material such as gastric acid from a perforated ulcer. Peritonitis can be classified as primary (Haematogenous dissemination), secondary (Due to perforation or trauma), or tertiary (Persistent or recurrent infection after adequate initial therapy).

Primary peritonitis is most often spontaneous bacterial peritonitis (SBP) caused by chronic liver disease. Secondary peritonitis is by far the most common form of peritonitis encountered in clinical practice.

Financial or Other, Competing Interest: None.

Submission 18-01-2016, Peer Review 17-02-2016,

Acceptance 22-02-2016, Published 05-03-2016.

Corresponding Author:

Dr. Sachin $V$,

3371, 20-E, Main $2^{\text {nd }}$ Stage,

Vijayanagar, Mysore-570017.

E-mail: sachinv701@gmail.com

DOI: $10.14260 /$ jemds $/ 2016 / 221$
Tertiary peritonitis often develops in the absence of the original visceral organ pathology. Earlier, Rawlenson in the year 1727 was the first to give clear description of signs and symptoms of gastric ulcer and peritonitis. ${ }^{1}$

The spectrum of aetiology of perforation in tropical countries continues to be different from its western counterparts. In contrast to western countries where lower gastrointestinal tract perforations predominate, upper gastrointestinal perforations constitute the majority of cases in India. ${ }^{2}$

Perforation of duodenal ulcer allows spillage of gastric and duodenal contents into the peritoneal cavity with a resulting initial chemical peritonitis. If there is continuing leakage of gastroduodenal contents, bacterial contamination of the peritoneal cavity can occur. The advent of proton pump inhibitors and helicobacter pylori eradication in the management of chronic peptic ulcer disease has reduced the incidence of operative treatment of this condition and its complications. But still perforated duodenal ulcer remains a major life threatening complication of chronic peptic ulcer disease.

Despite advances in surgical techniques, antimicrobial therapy and intensive care support, management of peritonitis continues to be highly demanding, difficult and complex. 
The main stay of treatment for bowel perforation is surgery. Endoscopic, laparoscopic and laparoscopic-assisted procedures are now being increasingly performed instead of conventional laparotomy. 3,4 There is paucity of data on the clinical presentation and spectrum of perforation peritonitis from Indian subcontinent. Hence this study was undertaken to highlight clinical profile and management of patients presenting with perforation peritonitis. The main objective is to study the frequency of peritonitis secondary to hollow viscus perforation in relation to age, sex, anatomical location, symptoms and signs, reliability of investigation like erect X-ray abdomen and to study the surgical management and its complications.

\section{MATERIALS AND METHODS}

The present study was carried out at the department of general surgery, K. R. Hospital attached to Department of General Surgery, Mysore Medical College and Research Institute.

Study Design: prospective, descriptive study.

Study Period: September $1^{\text {st }} 2014$ to august $31^{\text {st }} 2015$ - 1 year Sample size: 60 .

All patients admitted under the study were put to detailed history taking including history of acid peptic disease, prolonged use of NSAIDs, abdominal trauma, smoking or any other diseases related to cause perforation. A thorough and complete clinical examination was done. All patients were stabilized hemodynamically. Pre-operative antibiotics usually a combination of third generation I.V. cephalosporins and metronidazole were administered. All routine investigations were done including complete haemogram, blood grouping, renal function tests, serum electrolytes and bedside E.C.G.

Specific investigations in the form of Erect X-ray abdomen including both domes of diaphragm and ultrasound abdomen were done. C.T. scan of abdomen was conducted on patients where diagnosis of perforation peritonitis was doubtful. After confirmation of diagnosis patients underwent emergency explorative laparotomy. The site of perforation, size, number, its pathological condition and amount of peritoneal contamination were determined. Biopsies were taken from perforation edges whenever required. The procedures adopted in the management were omental patch closure, simple double layer closure, open appendectomy, resection and anastomosis, and loop ileostomy.

In every case thorough normal saline peritoneal lavage was given. Two abdominal drains were provided and wound closed in layers. All patients were followed post-operatively by nil per-oral, Ryle's tube aspiration, intravenous fluids and antibiotic coverage. Complications if occurred were vigorously managed. Patients were allowed oral diet after return of bowel sounds.

\section{Ethics}

The study was done within the ethical standards of the responsible institutional committee.

\section{RESULTS}

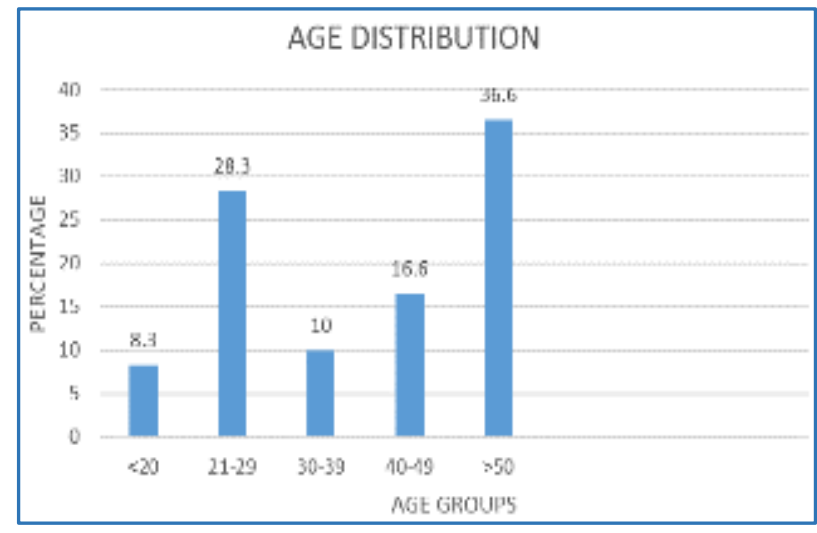

Fig. 1: Chart showing Age Distribution

The maximum number of patients were in the age group of more than 50 years (22 patients).

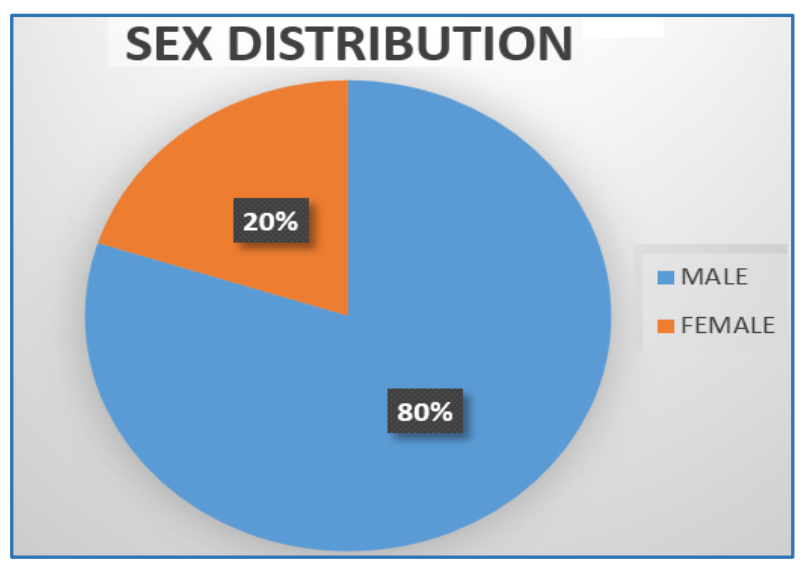

Fig. 2: Chart showing Sex Distribution

Out of 60 patients $48(80 \%)$ were males and $22(20 \%)$ were females.

\section{Clinical Features}

\begin{tabular}{|c|c|c|}
\hline Symptoms & No. of Cases & Percentage \% \\
\hline Pain abdomen & 60 & 100 \\
\hline Vomiting & 25 & 41.66 \\
\hline Fever & 8 & 13.33 \\
\hline Constipation & 2 & 3.33 \\
\hline Trauma & 2 & 3.33 \\
\hline
\end{tabular}

\begin{tabular}{|c|c|c|}
\hline Signs & $\begin{array}{c}\text { No. of } \\
\text { Cases }\end{array}$ & $\begin{array}{c}\text { Percentage } \\
\%\end{array}$ \\
\hline Distension of abdomen & 30 & 50 \\
\hline Dehydration & 40 & 66.66 \\
\hline Guarding, Rigidity & 50 & 83.33 \\
\hline Obliteration of liver dullness & 42 & 70 \\
\hline Free fluid in abdomen & 36 & 60 \\
\hline Table 2: Clinical features (Signs) of cases studied. \\
\hline
\end{tabular}




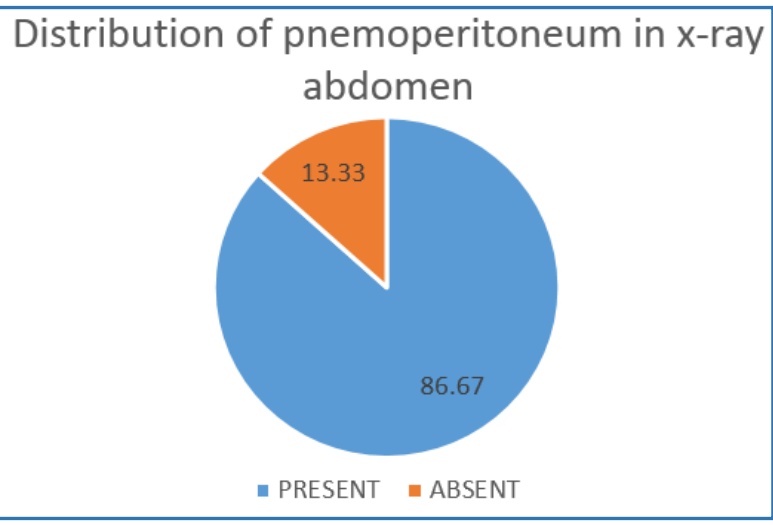

Fig. 3: Chart showing distribution of pneumoperitoneum

\section{In erect X-ray Abdomen}

Gas under diaphragm was seen in 52 cases (86.67\%) irrespective of the site of perforation which is statistically significant.

\section{Site of Perforation}

\begin{tabular}{|c|c|c|}
\hline Anatomical Site & $\begin{array}{l}\text { No. of } \\
\text { Cases }\end{array}$ & $\begin{array}{c}\text { Percentage } \\
\text { (\%) }\end{array}$ \\
\hline Stomach & 4 & 6.66 \\
\hline Duodenum & 30 & 50 \\
\hline Jejunum & 2 & 3.33 \\
\hline Ileum & 15 & 25 \\
\hline Appendix & 8 & 13.33 \\
\hline Colon & 1 & 1.66 \\
\hline \multicolumn{3}{|c|}{ Table 3: Anatomical site of perforation } \\
\hline
\end{tabular}

\section{Types of Operation}

\begin{tabular}{|c|c|c|}
\hline Surgery Performed & $\begin{array}{c}\text { No. of } \\
\text { Patients }\end{array}$ & $\begin{array}{l}\text { Percentage } \\
\text { (\%) }\end{array}$ \\
\hline Omental patch closure & 34 & 56.66 \\
\hline Appendectomy & 8 & 13.33 \\
\hline $\begin{array}{c}\text { Simple closure (two } \\
\text { layers) }\end{array}$ & 7 & 11.66 \\
\hline Resection anastomosis & 6 & 10 \\
\hline Loop ileostomy & 5 & 8.33 \\
\hline \multicolumn{3}{|c|}{ Type 4: Types of operations performed. } \\
\hline
\end{tabular}

\section{Complications}

\begin{tabular}{|c|c|c|}
\hline Complications & No. of Patients & $\begin{array}{c}\text { Percentage } \\
\text { (\%) }\end{array}$ \\
\hline Intra-abdominal abscess & 2 & 3.3 \\
\hline Wound infection & 12 & 20 \\
\hline LRTI & 20 & 33.33 \\
\hline ARDS & 1 & 1.67 \\
\hline Fecal fistula & 1 & 1.67 \\
\hline Wound dehiscence & 1 & 1.67 \\
\hline Paralytic ileus & 5 & 8.33 \\
\hline \multicolumn{2}{|c|}{ Table 5: Post-operative complications } \\
\hline
\end{tabular}

\section{Outcome}

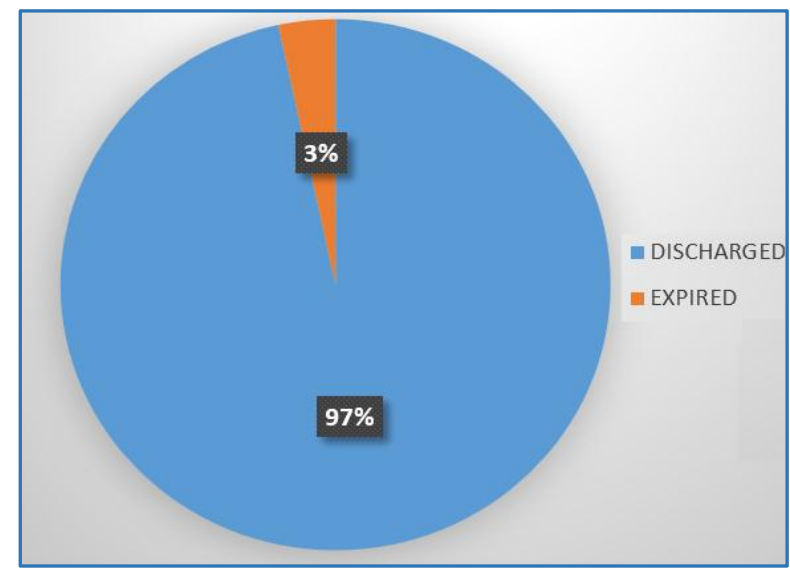

Fig. 4: Distribution of sample by outcome.

Out of 60 patients 2 patients died, having a mortality rate of $3.33 \%$.

\section{DISCUSSION}

This study was conducted in K. R. Hospital attached to Mysore Medical College \&Research Institute. A total of 60 patients admitted with peritonitis due to hollow viscous perforation were selected by simple random technique. The highest number of patients encountered in this series were in the age group of 50 years and above followed by age group of 21-29 years. Mean age of presentation is 52.73 years in this study which is comparable to the mean age of 49 years found by Singh G et al. ${ }^{5}$

The ratio of men to women with all types of perforation irrespective of site and pathological condition was $4: 1$. Different authors have found variable results with regard to sex ratio. Ramesh C Bharati et al. reported sex ratio of 24:1 in their review of 50 cases. MacKay and MacKay reported a male to female ratio of 19:1. In our study, the most frequent cause of peritonitis was duodenal ulcer perforations (50\%), followed by small bowel perforations (25\%) and appendicular perforations (13.33\%). Our results are in agreement with a number of other studies previously done indicating that duodenal ulcer perforations are the commonest, followed by small bowel and appendicular perforation, in this region of the world. $6,7,8$

In the present study, pain abdomen was present in all cases. Guarding and rigidity was present in 50 patients, liver dullness was obliterated in 42 patients and not obliterated in 18 patients. Probable reasons suggested are sealing of perforation or lack of gas at the site of perforation or adhesions around the site of perforations. Perforated peptic ulcer is becoming common in older patients and associated with higher incidence of recent consumption of non-steroidal antiinflammatory drugs. In the present study, perforated peptic ulcer constituted $56.66 \%$ of hollow viscous perforation. A plain X-ray of the abdomen in the erect posture indicated that $86.66 \%$ of cases had gas under the diaphragm.

The higher incidence of wound infection may be because majority $(20 \%)$ of patients presented late ( $>48$ hours) to the hospital with well-established peritonitis and majority were in older age group. ${ }^{9}$ The most common post-operative complication observed was lower respiratory tract infection. 


\section{CONCLUSION}

- The most common age group affected is 50 years and above.

- Duodenal ulcer perforations were more common in the age group of 50 years and above.

- Most of these patients present with clinical signs of peritonitis 48 hours after the onset of pain.

- $80 \%$ of the patients were male and $20 \%$ of the patients were female.

- Duodenum (50\%) is the most common site of perforation followed by ileal perforation $(25 \%)$ and appendicular perforation (13.33\%).

- Guarding and rigidity were present in $83.33 \%$ of patients.

- Diagnosis is made clinically and confirmed by presence of pneumoperitoneum $(86.66 \%)$ on radiographs.

- Laparotomy with closure of the perforation with omental patch $(56.66 \%)$ is the commonest operative management for perforated peptic ulcer.

- The most common postoperative complication observed was lower respiratory tract infection.

- $\quad$ The overall mortality was $3.33 \%$.

- Presentation of patients immediately after the first symptom and timely surgical intervention are the keys to successful battle against secondary peritonitis.

- The most important factor clearly deciding the fate of the patients is eliminating the source of infection. The omental patch procedure is a simple and very effective method for closure of any size of perforations.

- The incidence of secondary peritonitis can be tackled efficiently by better use of guidelines, appropriate use of prophylactic antibiotics and timely intervention by surgeons.

\section{REFERENCES}

1. Danapat MC, Mukherjee SB, Mishra PC. Howlader gastrointestinal perforations Indiasn of surgery. 1991;53(5):189-93.

2. Rajender Singh Jhobta, Ashok Kumar Attri, Robin Kaushik, et al. Spectrum of perforation peritonitis in India-review of 504 consecutive cases. World J Emerg Surg 2006;1:26.

3. Siu WT, Chau CH, Law BK, et al. Routine use of laparoscopic repair for perforated peptic ulcer. Br J Surg 2004;91:481-484.

4. Hainaux B, Agneessens E, Bertinotti R, et al. Accuracy of MDCT in predicting site of gastrointestinal tract perforation. AJR Am J Roentgenol 2006;187:1179-1183.

5. Singh G, Sharma RK, Gupta R. Gastrointestinal perforations-a prospective study of 342 cases. Gastroentrol Today 2006;10(4):167-70.

6. Gupta S, Kaushik R. Peritonitis-the eastern experience. World J Emerg Surg 2006;1:13.

7. Khan S, Khan IU, Aslam S, et al. Retrospective analysis of abdominal surgeries at Nepalgunj medical college, Nepalgunj, Nepal: 2 year's experience. Kathmandu Univ Med J (KUMJ) 2004;2:336-43.

8. Yadav SS, Srinarayan. An experience with cases of peritonitis at Bheri Zonal hospital, Nepalgunj. J Soc Surg Nepal 2002;5:33-36.

9. Mathikere Lingaiah Ramachandra, Bellary Jagadesh, Sathees BC Chandra. Clinical study and management of secondary peritonitis due to perforated hollow viscous. Arch Med Sci 2007;3:61-68. 